\title{
Evaluasi sistem sanitasi di rumah susun Kota Palangka Raya
}

\author{
H. P. Jaya ${ }^{1 *}$, S. Swastila ${ }^{2}$, Y. Ludang ${ }^{3}$ \\ ${ }_{1}^{1}$ Program Studi Doktoral Ilmu Lingkungan, Universitas Palangka Raya, Palangka Raya, Indonesia \\ ${ }_{2}^{2}$ Program Studi Farmasi, Universitas Brawijaya, Malang, Indonesia \\ 3Jurusan Kehutanan, Fakultas Pertanian, Universitas Palangka Raya, Palangka Raya, Indonesia
}

\begin{abstract}
Abstrak.
Kota Palangka Raya memiliki luas wilayah $2.678,51 \mathrm{~km}^{2}$, jumlah penduduk 229.599 jiwa dan kepadatan penduduk rata-rata $85,72 \mathrm{jiwa} / \mathrm{km}^{2}$. Kota ini mengalami kemajuan cukup pesat sehingga berdampak terhadap semakin mahalnya harga tanah di daerah perkotaan. Salah satu kebijakan pemerintah untuk mengatasi permasalahan tersebut dengan membangun rumah susun yang terjangkau bagi masyarakat menengah ke bawah. Aspek kenyamanan, sanitasi dan keamanan bagi penghuni rumah susun merupakan faktor utama yang menjadi perhatian. Pemerintah Kota Palangka Raya membangun rumah susun pertama tahun 2005 di Jalan Sesep Madu RT 02/RW 09 Kelurahan Palangka, Kecamatan Jekan Raya, Kota Palangka Raya dan mulai dihuni awal tahun 2010. Tulisan ini bertujuan untuk mengevaluasi sistem sanitasi di rumah susun Kota Palangka Raya. Metode yang digunakan dengan cara observasi dan wawancara langsung terhadap pengelola dan beberapa penghuni rumah susun. Hasil observasi menunjukkan kondisi bangunan rumah susun kurang terawat, terkesan kumuh, kondisi hunian belum berfungsi secara optimal (pada lantai 5 terdapat 24 kamar tidak dihuni karena penerangan listrik diputus oleh Perusahaan Listrik Negara akibat menunggak), sistem sanitasi seperti air bersih tersedia tetapi air limbah, drainase dan persampahan tidak dikelola dengan baik.
\end{abstract}

Kata kunci: kota Palangka Raya, rumah susun, sanitasi

\begin{abstract}
.
The municipal city of Palangka Raya $\left(2,678.51 \mathrm{~km}^{2}\right)$ is populated by 229,599 inhabitants with the average population density around 85.72 inhabitant $/ \mathrm{km}^{2}$. The city is progressing quite rapidly causing on the increasingly land prices in urban areas. Then the multi-level housing construction will be the right and proper government policy to overcome the problem in order to make affordable housing for lower middle class society. There are supporting factors to concern, those are comfortability, sanitation and security. The first multi-level housing was located on Sesep Madu Street RT 02/RW 09, Palangka Sub-district of Jekan Raya, Palangka Raya, constructed in 2005 and started being inhabited in the beginning of 2010. The objective of this article was to evaluate the sanitation system of the multilevel housing in Palangka Raya. Methods consisted of observation and direct interview to the management and inhabitans of the multi-level housing residence. The observation indicated that the housing condition was not well maintained and looked slum, occupancy management had not been functioned optimally where there were 24 rooms unoccupied on the 5th level since the electricity was shut off by the State Electricity Company (PLN) because of arrears, meanwhile the sanitation system such as clean water was well provided whereas waste and drainage system was in poor management.
\end{abstract}

Keywords: Palangka Raya municipality, multi-level housing, sanitation

\section{PENDAHULUAN}

Pertambahan jumlah penduduk akibat kelahiran dan perpindahan penduduk menimbulkan masalah tersendiri bagi pembangunan di perkotaan. Dampak langsung yang dihadapi oleh pemerintah kota adalah semakin sempitnya lahan yang tersedia bagi penduduk, akibatnya persaingan untuk mendapatkan tempat tinggal menjadi masalah tersendiri. Ketidakmampuan masyarakat yang berpenghasilan rendah untuk memiliki tempat tinggal menyebabkan adanya rumah yang sempit dan kumuh di perkotaan dan berimplikasi pada permasalahan sosial. Ehlers and Steel (1979) menyatakan bahwa jika dilihat dari segi kenyamanan dan kesehatan, tempat tinggal tersebut

\footnotetext{
${ }^{*}$ Korespondensi Penulis

Email : herry_jaya@pasca.upr.ac.id
} 
tidak layak huni tetapi karena kondisi ekonomi yang tidak memungkinkan membuat mereka tetap bertahan di tempat tersebut. Konsep pembangunan ke arah vertikal seperti rumah susun, flat dan kondominium akan dapat melipatgandakan daya dukung lahan yang ada di wilayah kota.

Adanya pembangunan rumah susun merupakan kebijakan pemerintah yang tepat sehingga memungkinkan masyarakat tingkat ekonomi menengah ke bawah dapat turut memanfaatkan kesempatan tersebut. Sekitar tahun 1990-an, pembangunan rumah susun dengan sistem sewa merupakan alternatif untuk masyarakat dengan penghasilan rendah (Yudhohusodo 1990), yaitu (1) Untuk masyarakat berpenghasilan rendah yang tidak memiliki pendapatan dan pekerjaan tetap, sehingga sulit untuk memanfaatkan fasilitas perumahan (2) Masyarakat yang tinggal tidak menetap karena pekerjaan (3) Masyarakat yang belum mendapat kesempatan memiliki rumah sendiri secara permanen (4) Bagi mereka yang baru berumah tangga dan belum memiliki rumah. Menurut Mangkoedihardjo dan Samudro (2010), beberapa faktor yang mendukung tercapainya aspek kenyamanan dan keamanan bagi penghuni rumah susun adalah tersedianya fasilitas sanitasi yang memenuhi persyaratan kesehatan yaitu adanya sistem penyediaan air bersih, pembuangan air limbah, drainase, pembuangan sampah, adanya fasilitas mandi, cuci, kakus (MCK) dan utilitas lainnya.

BPS Kota Palangka Raya (2013) menyebutkan bahwa luas Kota Palangka Raya adalah 2.678,51 $\mathrm{km}^{2}$, berpenduduk sebanyak 229.599 jiwa dengan kepadatan penduduk rata-rata $85,72 \mathrm{jiwa} / \mathrm{km}^{2}$. Pembangunan rumah susun di Kota Palangka Raya dilaksanakan tahun 2005, mulai dihuni awal tahun 2010, tetapi dalam perkembangan selanjutnya hingga kini masih terlihat kondisi fisik rumah susun dan prasarana lingkungannya sering terabaikan oleh penghuninya dan mengakibatkan terjadinya penurunan kualitas dan kuantitas pelayanan sistem sanitasi. Kesibukan dan tidak ada waktu luang serta biaya operasional dan perawatan yang tidak ada menjadi kendala yang dialami penghuni, sehingga menyebabkan kekumuhan dan penurunan kualitas pelayanan sistem sanitasi di rumah susun.

Tujuan penelitian ini adalah mengevaluasi sistem sanitasi di rumah susun Kota Palangka Raya, diharapkan dapat memberikan informasi kepada pihakpihak yang terkait khususnya pemerintah daerah dan masyarakat Kota Palangka Raya terkait sistem sanitasi rumah susun, sehingga pemerintah lebih dapat menanamkan rasa kepekaan dan kepedulian terhadap lingkungan khususnya bagi masyarakat Kota Palangka Raya akan pentingnya menjaga sistem sanitasi dari kerusakan, baik dampak buruk yang akan terjadi dalam jangka pendek, menengah maupun panjang, sehingga pencegahan sejak dini akan berdampak positif untuk masa yang akan datang. 
Bertitik tolak dari permasalahan tersebut, maka dilakukan evaluasi sistem sanitasi di rumah susun Kota Palangka Raya. Adanya sistem sanitasi yang baik akan membuat lingkungan di rumah susun Kota Palangka Raya menjadi terpelihara, serta dapat membantu perwujudan Palangka Raya menjadi kota yang aman, menarik, sesuai semboyan Kota Palangka Raya "Cantik" yaitu terencana, aman, nyaman, tertib, indah dan keterbukaan.

\section{METODOLOGI}

\subsection{Lokasi kajian dan waktu penelitian}

Lokasi penelitian dilaksanakan di rumah susun Jalan Sesep Madu RT 02/RW 09, Kelurahan Palangka, Kecamatan Jekan Raya, Kota Palangka Raya, Provinsi Kalimantan Tengah. Pelaksanaan waktu penelitian selama 1 bulan sejak tanggal 28 Juni sampai dengan 28 Juli 2017.

\subsection{Prosedur analisis data}

Pengumpulan data utama dilakukan dengan wawancara langsung terhadap pengelola dan beberapa penghuni rumah susun, sedangkan data penunjang diperoleh melalui studi pustaka baik dari buku maupun internet. Data pembanding yang ditampilkan berupa visual kondisi rumah susun pada tahun 2012.

\section{HASIL DAN PEMBAHASAN}

\subsection{Kondisi fisik bangunan}

Umur bangunan rumah susun sudah mencapai 7 tahun. Hasil penelitian di lapangan bahwa kondisi fisik bangunan baik komponen maupun struktural masih bagus namun tidak terawat dengan baik, terlihat saat kondisi tahun 2012 (Gambar 1) dan saat kondisi tahun 2017 (Gambar 2).

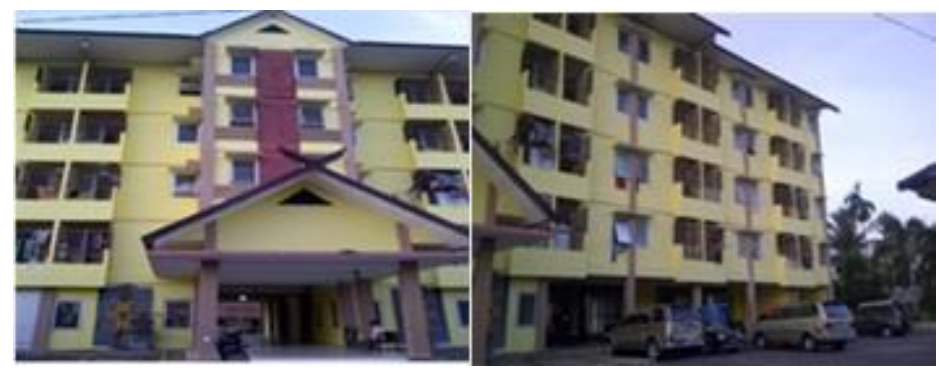

Gambar 1. Rumah susun tampak depan dan samping, kondisi tahun 2012. 


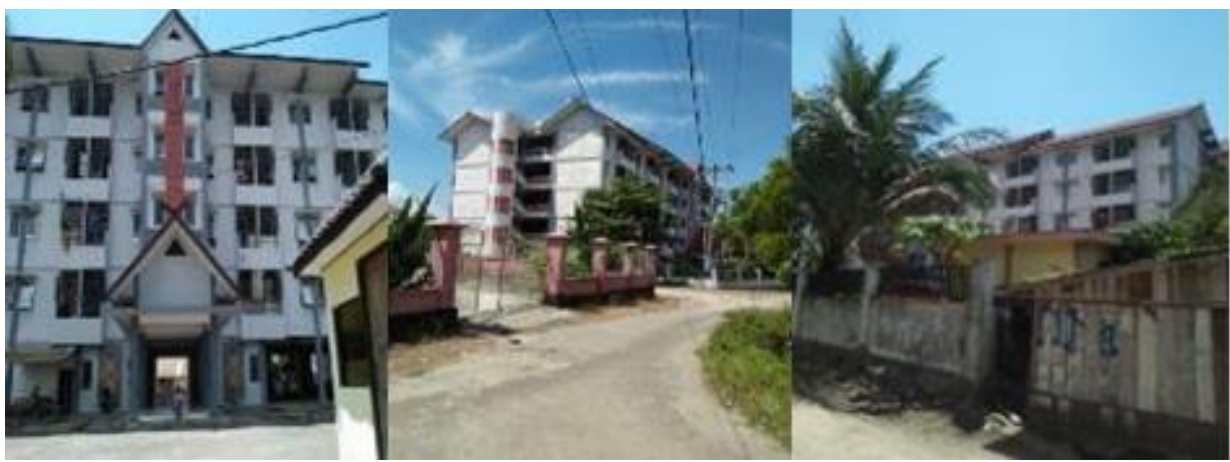

Gambar 2. Rumah susun tampak depan dan samping, kondisi tahun 2017.

Akses pergerakan penghuni rumah susun dari lantai bawah menuju ke lantai atas atau sebaliknya menggunakan tangga. Tangga yang terdapat di lantai 1 dan 2 yang ada penghuninya cukup bersih, sedangkan lantai 3, 4 dan 5 tidak terawat dan sangat kotor, halaman parkir untuk mobil dan sepeda motor yang cukup luas namun tidak terawat, terlihat saat kondisi tahun 2012 (Gambar 3) dan saat kondisi tahun 2017 (Gambar 4).

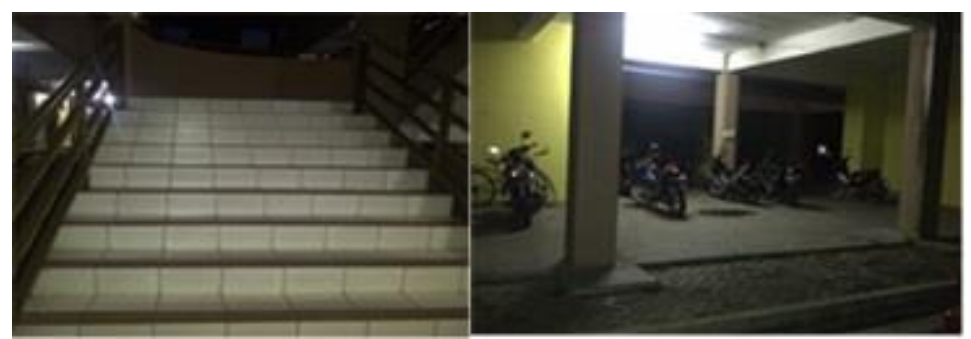

Gambar 3. Tangga umum dan halaman parkir rumah susun, kondisi tahun 2012.

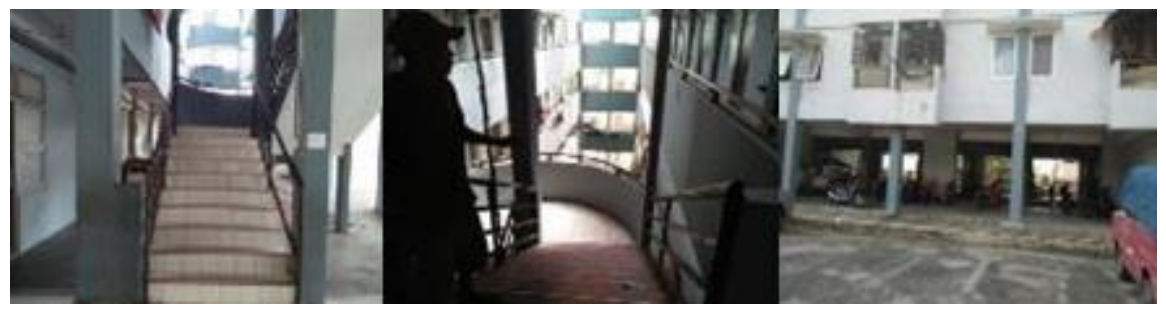

Gambar 4. Tangga umum dan halaman parkir rumah susun, kondisi tahun 2017.

\subsection{Kondisi Hunian}

Rumah susun ini hanya memiliki 1 tipe hunian yaitu tipe 30 dengan ukuran $4 \times 5 \mathrm{~m}^{2}$, terdiri atas 5 lantai dengan harga sewa bervariasi. Lantai 1 diperuntukkan sebagai tempat pertokoan (namun kenyataannya hanya 
dimanfaatkan sebagai gudang) dengan biaya sewa sebesar Rp 175.000 per bulan, lantai 2 hingga lantai 5 diperuntukkan sebagai tempat hunian dengan biaya sewa untuk lantai 2 sebesar Rp 200.000 per bulan, sedangkan lantai 3 sebesar Rp 175.000 per bulan, serta lantai 4 dan 5 sebesar Rp 150.000 per bulan. Jumlah anggota keluarga dalam unit satuan rumah susun yang sudah berkeluarga dengan 2 orang dewasa dan 2 orang anak, ada juga dengan 1 orang anak. Di rumah susun tersebut terdapat 96 kamar, 61 kamar telah dihuni, sedangkan 35 kamar masih kosong. Setiap kamar terdiri atas ruang multifungsi, ruang dapur, ruang jemur serta ruang mandi, cuci dan kakus, terlihat saat kondisi tahun 2012 (Gambar 5) dan saat kondisi tahun 2017 (Gambar 6) serta kondisi dapur, ruang jemur dan MCK saat kondisi tahun 2017 (Gambar 7).

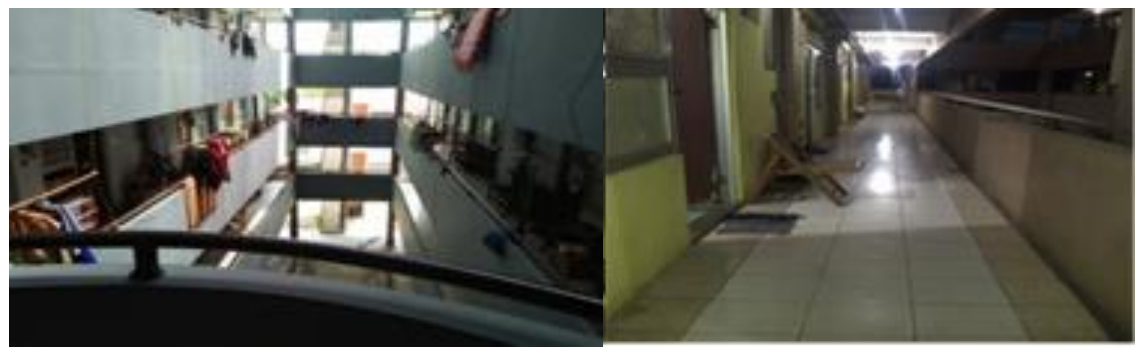

Gambar 5. Sudut rumah susun pada lantai 2, kondisi tahun 2012.

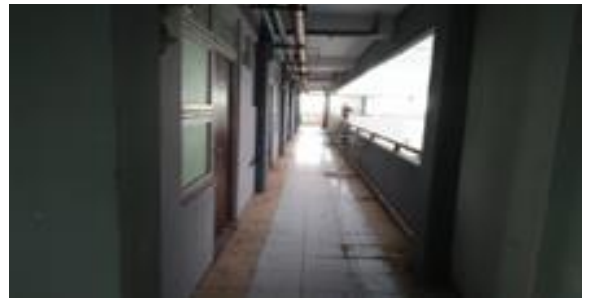

Gambar 6. Sudut rumah susun pada lantai 2, kondisi tahun 2017.
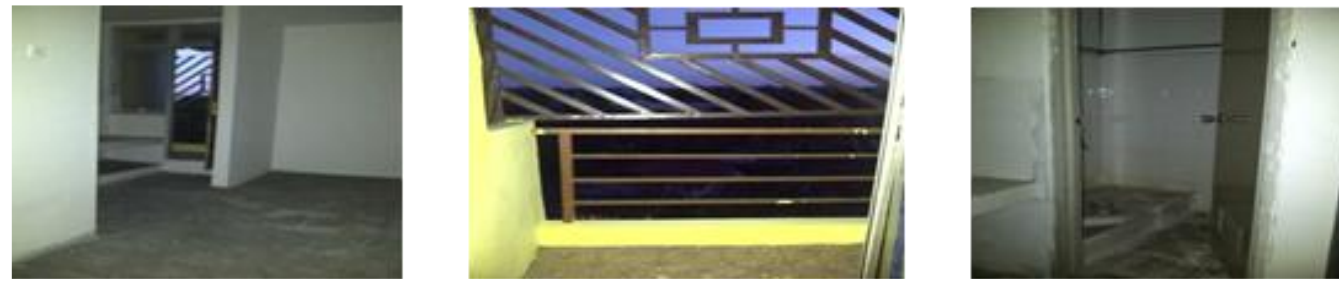

Gambar 7. Dapur, ruang jemur dan MCK, kondisi tahun 2017. 
Rumah susun ini juga memiliki ruang bersama yang berfungsi untuk tempat pertemuan dan ruang bermain pada setiap lantai, terlihat saat kondisi tahun 2012 (Gambar 8) dan saat kondisi tahun 2017 (Gambar 9).
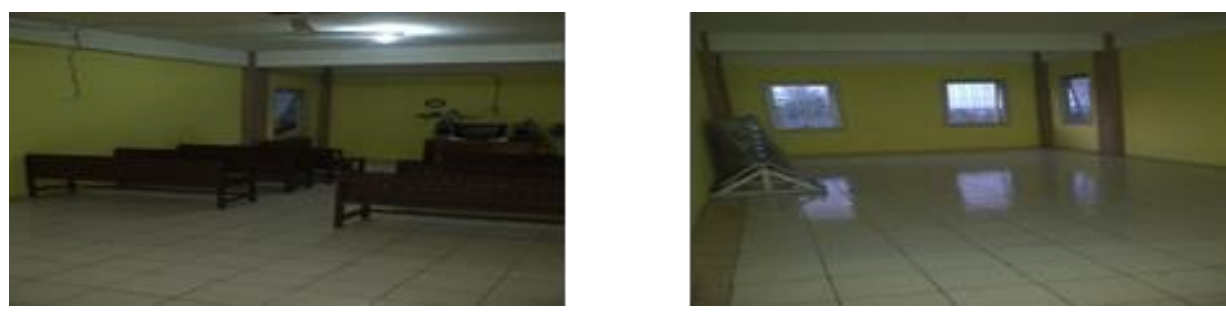

Gambar 8. Ruang bersama dan ruang bermain rumah susun, kondisi tahun 2012.

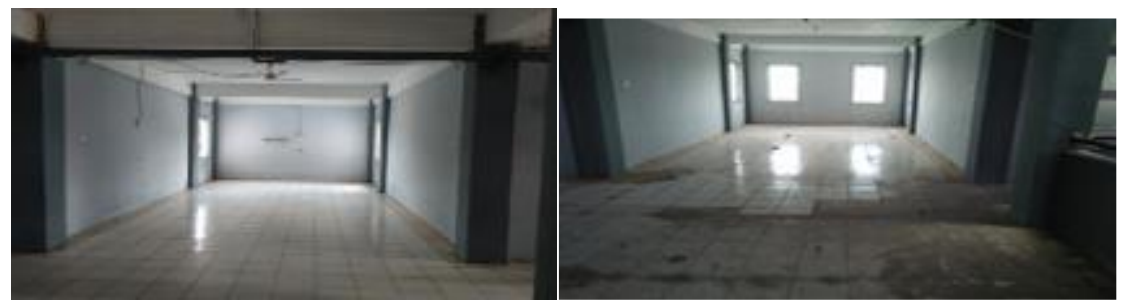

Gambar 9. Ruang bersama dan ruang bermain rumah susun, kondisi tahun 2017.

\subsection{Kondisi Sistem Sanitasi}

\subsubsection{Air Bersih}

Sistem penyediaan air bersih di rumah susun dilakukan secara swadaya masyarakat, setiap penghuni diwajibkan untuk membayar iuran sebesar Rp 35.000 setiap bulan. Kebutuhan air bersih di rumah susun berasal dari reservoir bawah tanah dan pompa. Air yang berasal dari pompa dialirkan menuju banker penyimpanan air menggunakan pipa. Air yang ditampung di dalam banker kemudian dialirkan menuju tangki air pada lantai 6, terlihat kondisi tahun 2017 (Gambar 10). Untuk konsumsi air minum masing-masing penghuni membeli air minum isi ulang.
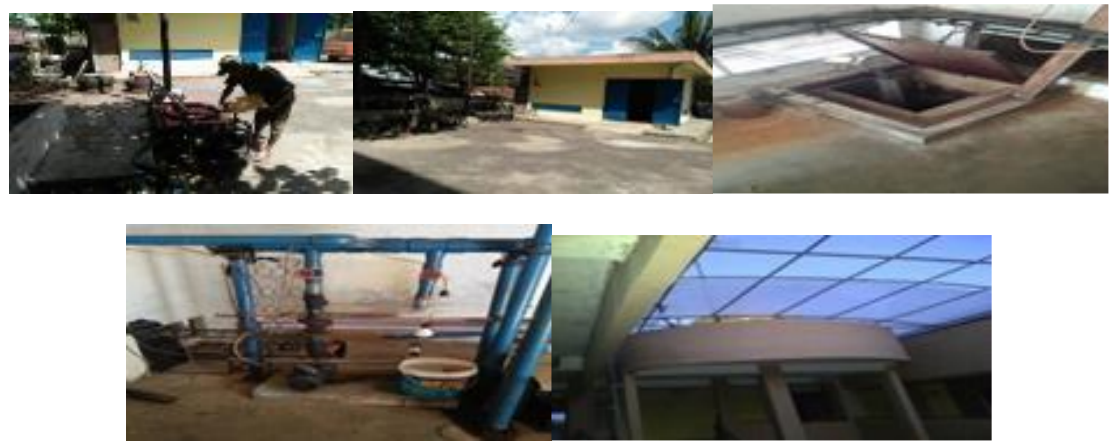

Gambar 10. Banker air, alat pemindah air dan tangki air, kondisi tahun 2017. 


\subsubsection{Air Limbah}

Sumber air limbah terutama dihasilkan dari limbah rumah tangga (domestik). Penyaluran air limbah dari unit satuan rumah susun melalui pipa yang dibedakan berdasarkan jenis limbahnya yaitu limbah grey water dan black water. Untuk pembuangan air limbah yang berasal dari mandi, cuci dan masak (grey water) langsung disalurkan ke saluran drainase atau selokan yang ada di lingkungan rumah susun. Pembuangan air limbah yang berasal dari kakus/WC (black water) disalurkan langsung ke dalam tangki septik. Pengurasan tangki septik tidak dilakukan secara rutin dan pada saat penelitian tercium bau tidak nyaman.

\subsubsection{Drainase}

Saluran drainase yang terdapat di rumah susun langsung dialirkan menuju sungai. Sistem drainase di rumah susun adalah sistem tercampur (combined sewer). Saluran drainase selain menerima limpasan air hujan juga menerima buangan air limbah grey water, menimbulkan bau dan juga saluran drainase banyak terdapat sampah, terlihat kondisi tahun 2017 (Gambar 11).
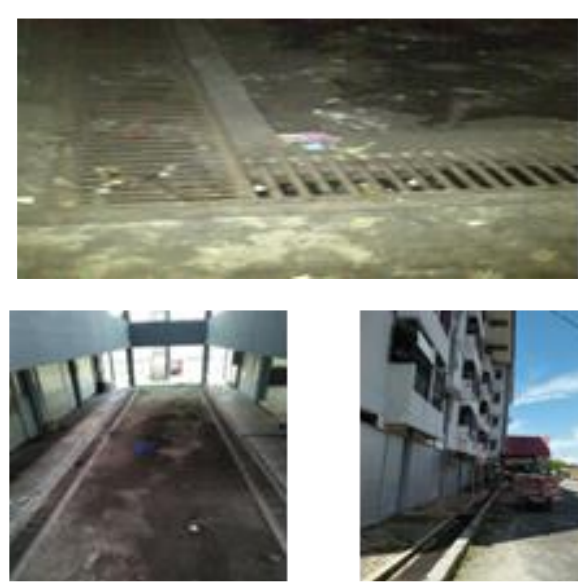

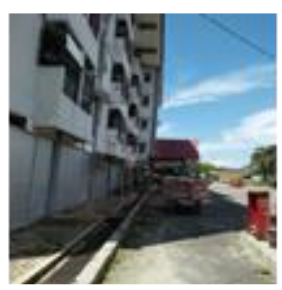

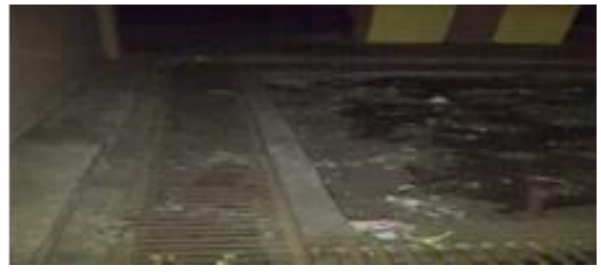
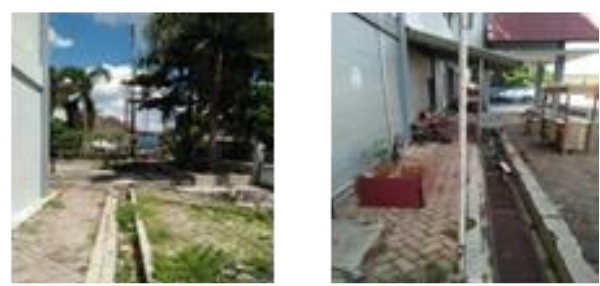

Gambar 11. Saluran drainase rumah susun, kondisi tahun 2017.

\subsubsection{Persampahan}

Sampah berasal dari beberapa tempat terutama dari dalam gedung rumah susun, terdiri dari (1) Unit satuan rumah susun yaitu dari dapur, kamar mandi dan sumber lain (2) Selasar yaitu berasal dari aktivitas penghuni terutama di ruang bersama (3) Sampah yang berasal dari luar gedung, dihasilkan dari jalan, tempat parkir mobil atau motor dan lain-lain. Sampah basah dan kering dicampur begitu saja dan diletakkan di Tempat Penampungan Sampah (TPS) dalam kondisi terbuka (tidak sesuai dengan aturan PP RI Nomor 81 Tahun 2012 
tentang pengelolaan sampah rumah tangga dan sampah sejenis sampah rumah tangga). Tiap unit satuan rumah susun tidak terdapat wadah sampah. Pada umumnya penghuni hanya menggunakan bahan kantong plastik (kresek) dengan kapasitas sesuai kebutuhan. Di selasar dan di ruang bersama tidak terdapat wadah sampah. Sampah-sampah tersebut sering tidak terangkut dengan sempurna, sehingga berserakan ditiup angin dan dibongkar oleh hewan seperti kucing dan anjing (Gambar 12).
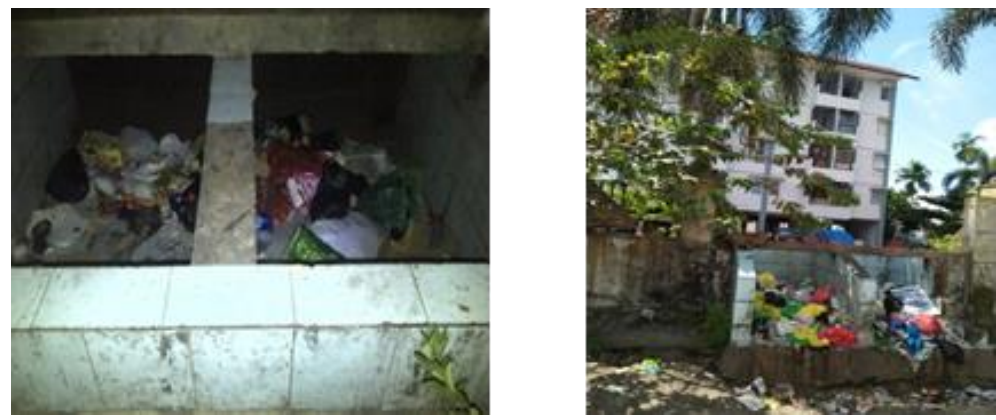

Gambar 12. Bak sampah/TPS depan rumah susun, kondisi tahun 2017.

Berdasarkan hasil uraian di atas, diketahui bahwa air limbah yang berasal dari grey water seharusnya tidak dialirkan begitu saja menuju sungai karena dampaknya begitu besar bagi lingkungan. Air limbah grey water tidak langsung dibuang ke saluran drainase, tetapi dimanfaatkan dahulu (reuse) dengan cara didaur ulang untuk keperluan penggelontoran (flushing), siram tanaman, pembersihan rumah dan keperluan non-konsumsi lainnya, disalurkan ke sumur resapan, kemudian ke saluran drainase. Sebelum proses daur ulang ini diterapkan, perlu dilakukan studi atau penelitian lanjutan tentang kemauan dan kesiapan penghuni rumah susun untuk memanfaatkan proses daur ulang.

Perbaikan yang perlu dilakukan dalam sistem drainase adalah dengan melakukan normalisasi, perawatan, pemeliharaan saluran, mengambil sampah yang ada di saluran drainase serta meningkatkan kesadaran masyarakat untuk tidak membuang sampah di saluran drainase dan kesadaran untuk menjaga kebersihan lingkungan rumah susun. Cara yang dilakukan adalah dengan melakukan sosialisasi dan penyuluhan kepada masyarakat akan pentingnya kebersihan lingkungan dan kesehatan lingkungan serta bahaya yang ditimbulkan akibat saluran drainase yang mampat yaitu dapat menimbulkan penyakit dan terjadi genangan bahkan banjir. Gotong royong dapat dilakukan di rumah susun minimal 2 kali dalam sebulan.

Pengolahan air limbah rumah tangga/domestik di rumah susun harus mengacu pada persyaratan teknis pembangunan rumah susun (PerMenPU Nomor 60/PRT/1992), yaitu: 
1. Saluran pembuangan air limbah yang berasal dari dapur, kamar mandi, cuci yang berada di dalam bangunan harus dilengkapi dengan pipa udara dan bak penampung atau bak kontrol dihubungkan dengan saluran pembuangan air limbah lingkungan.

2. Saluran pembuangan air limbah yang berasal dari kakus harus dipindahkan serta dilengkapi dengan pipa udara bak kontrol dan tangki septik.

Penanganan sampah di sumber sampah merupakan kegiatan awal pengelolaan sampah. Penghuni mempunyai peran yang sangat penting untuk mengurangi jumlah timbunan sampah seperti yang diatur dalam PerMenPUPR Nomor 01/Prt/M/2018 tentang bantuan pembangunan dan pengelolaan rumah susun.

Silas (2003) menyebutkan bahwa kegiatan penanganan sampah dapat dilakukan dengan pendekatan 5R (Reduce, Reuse, Recovery, Recycle, Revalue) yang sesuai dan bahkan lebih baik dari pendekatan yang diatur dalam PerMenLH Nomor 13 Tahun 2012 tentang pedoman pelaksanaan reduce, reuse dan recycle melalui bank sampah. Selain itu, upaya yang dapat dilakukan adalah dengan menimbulkan kesadaran penghuni dengan cara sosialisasi dan penyuluhan untuk melakukan upaya reduksi dan pemilahan sampah basah dan sampah kering mulai dari sumber atau unit satuan rumah susun, sehingga volume sampah yang dihasilkan lebih sedikit dan pemilahan ini dimaksudkan agar mudah dalam pengolahan selanjutnya.

Wadah sampah di dalam unit satuan rumah susun harus disediakan, baik oleh penghuni maupun pengelola. Jumlah wadah sampah minimal 2 buah yaitu satu khusus sampah basah dan satu untuk sampah kering. Pewadahan sampah bertujuan untuk menghindari kekumuhan atau sampah berserakan, memudahkan dalam proses pengumpulan, menghindari pembentukan dan penyebaran lindi serta menghindari timbulnya bau dan penyebaran penyakit. Hal ini sesuai dengan komitmen pemerintah dalam PP RI Nomor 88 Tahun 2014 tentang pembinaan penyelenggaraan perumahan dan kawasan permukiman untuk melakukan peningkatan kualitas terhadap perumahan kumuh dan permukiman kumuh. Kriteria yang harus dipenuhi dalam pewadahan sampah adalah tertutup, kokoh, kuat/tidak mudah rusak, kedap air, volume memadai, mudah dioperasikan, mudah diperbaiki dan mudah didapat. Khusus untuk wadah sampah basah hendaknya sampah yang dibuang sudah dimasukkan ke dalam kantong plastik/kresek terlebih dahulu atau wadah sampah dilapisi dengan kantong plastik. Hal ini dilakukan agar sampah basah tidak tercecer dan tidak menimbulkan bau.

Diperlukan penghijauan pada lahan-lahan yang kosong di lingkungan rumah susun. Penghijauan dapat dilakukan dengan penanaman tumbuhtumbuhan dan sayur-sayuran, sehingga dapat dimanfaatkan kembali. Bukan 
hanya sistem sanitasinya yang terjaga, tapi lingkungan pun menjadi hijau. Hijaunya lingkungan tidak hanya menjadikan lingkungan itu indah dan sejuk, namun aspek kelestarian, keserasian, keselarasan dan keseimbangan sumber daya alam terjaga.

\section{KESIMPULAN DAN SARAN}

\subsection{Kesimpulan}

Kondisi rumah susun di Jalan Sesep Madu RT 02/RW 09, Kelurahan Palangka, Kecamatan Jekan Raya, Kota Palangka Raya, Provinsi Kalimantan Tengah meliputi kondisi fisik bangunan, kondisi hunian dan kondisi sistem sanitasi tidak berjalan dengan baik. Sistem sanitasi rumah susun tersebut harus diperhatikan seperti air limbah, drainase dan persampahan karena berdasarkan hasil penelitian bahwa sistem sanitasi ini tidak mendapatkan perhatian dari penghuni, pengelola dan otoritas seperti Satuan Operasi Perangkat Daerah (SOPD) terkait di Kota Palangka Raya.

\subsection{Saran}

Penghuni rumah susun agar selalu dibina secara kontinu, sehingga memahami betapa pentingnya sanitasi terutama masalah air bersih, air limbah, drainase dan persampahan oleh Satuan Operasi Perangkat Daerah (SOPD) terkait di Kota Palangka Raya. Disamping itu otoritas setempat melalui SOPD secara rutin menganggarkan secara terukur biaya perawatan. Penghuni rumah susun diajak untuk membuat kondisi lingkungan menjadi hijau agar lingkungan enak dipandang mata dan sejuk, dengan menanam jenis tanaman tertentu yang mampu mengatasi pencemaran baik di tanah, air dan udara di lingkungan sekitar rumah susun.

\section{DAFTAR PUSTAKA}

[BPS] Badan Pusat Statistik. 2013. Kota Palangka Raya Dalam Angka. Badan Pusat Statistik Kota Palangka Raya.

Ehlers VM and Steel EW. 1979. Municipal and rural sanitation. John Willy \& Sons Inc. New York.

Mangkoedihardjo S dan Samudro G. 2010. Fitoteknologi terapan. Graha Ilmu. Yogyakarta.

PerMenPU (Peraturan Menteri Pekerjaan Umum) Nomor 60/PRT/1992 tentang persyaratan teknis pembangunan rumah susun.

PerMenLH (Peraturan Menteri Lingkungan Hidup) Nomor 13 Tahun 2012 tentang pedoman pelaksanaan reduce, reuse dan recycle melalui bank sampah. 
PerMenPUPR (Peraturan Menteri Pekerjaan Umum dan Perumahan Rakyat) Nomor 01/Prt/M/2018 tentang bantuan pembangunan dan pengelolaan rumah susun.

PP RI (Peraturan Pemerintah Republik Indonesia) Nomor 81 Tahun 2012 tentang pengelolaan sampah rumah tangga dan sampah sejenis sampah rumah tangga.

PP RI (Peraturan Pemerintah Republik Indonesia) Nomor 88 Tahun 2014 tentang pembinaan penyelenggaraan perumahan dan kawasan permukiman.

Silas J. 2003. Dilema Pengelolaan Sampah di Surabaya, Masalah dan Kejanggalan Pemahaman [Prosiding]. Prosiding Seminar Nasional, Sampah Kota Masalah, Solusi dan Prospeknya. Institut Teknologi Adhi Tama Surabaya. Surabaya.

Yudhohusodo S. 1990. Rumah untuk Seluruh Rakyat. Yayasan Padamu Negeri. Jakarta. 